\title{
Large Scale Destructive Testing in an Undergraduate Structural Engineering Curriculum
}

\author{
Douglas C. Stahl, Richard A. DeVries \\ Milwaukee School of Engineering
}

\section{Background and Project Goals}

Most engineering educators would dismiss as a crackpot one who claimed that computers should not be used in the practice of structural engineering; most would agree that blind faith in the computer is an equally indefensible position. Many of us are not quite sure how to respond, however, to the opinion held by some senior engineers that reliance on a slide rule during their education and for much of their careers somehow allowed their generation to be more in touch with their engineering work. Parmelee [7], for example, states that "the structural engineer was in complete control of the computations," that "the exercise of 'engineering judgment' was possible at every step," and that the current modus operandi is dangerously different. Some of us who grew up post-slide rule but somehow managed to become decent engineers are baffled by these ideas: They better understood their calculations... their engineering judgment was better than ours... just because they used an old-fashioned calculator?

Ferguson's observation [6] of shifts in engineering programs' emphasis during the past half-century may shed more reasonable light on the issue. He noted that the emphasis has moved away from drawing studios, labs, shops, and plant visits, and focused instead on lectures and abstract analysis and computer simulation. The shift has been from active exploring and discovery to passive learning from book and lecture. As a result, students today have "no reason to believe that curiosity about the physical meaning of the subjects they [are] studying [is] necessary." Petroski [9] and Backman [1] make the related observation that some high profile engineering failures - as well as innumerable examples of poor design that do not result in catastrophe - are the result of engineers trying to apply theory they don't understand, rather than following an intuitive sense of how engineered systems behave.

The goal of the Structural Engineering Workshop at Milwaukee School Of Engineering is to re-kindle curiosity and to cultivate students' intuitive sense of structural behavior by helping them understand the links between real structural behavior and the abstract analysis and design procedures they are learning. One component of this project is a repertoire of large-scale experiments demonstrating that there are real (loud, interesting, and potentially dangerous) events behind important structural design abstractions. The other component is an interactive learning unit that allows the students to place each experiment into the context of their individual courses and program of study. The SEW enhances continuity of academic programs as students return to

the experiments and related activities at various times, each time considering them from the 
viewpoint of a different course.

A review of the literature showed that there have been several significant projects bringing structural experiments into the classroom. Most of them are limited in two respects that the SEW moves beyond: First, all include curricular enhancements conducted wholly within individual courses; no project that we are aware of has attempted to use the experiments as a means to integrate activities across the curriculum of an engineering discipline. Second, all have focused on structural design in an abstract sense (for example using noodles or straws instead of structural lumber or reinforced concrete), or on structural analysis of linear elastic systems, or used smallscale models that cannot always exhibit realistic failure modes.

Behr, Belarbi, and their colleagues [2, 3, with similar work described by 11] describe a structural analysis laboratory that combines physical experiment, computer analysis, and classical methods. They created a format in which teams of students compare analysis results and test results, and then consider the limitations of each phase of the work. The spirit of this work is what we are trying to achieve, but we are applying it to inelastic behavior and failure rather than elastic behavior. Schmucker [10] incorporated physical experiments into structural analysis courses, and described an enthusiastic student response to the small models illustrating moment resisting frames, suspension bridges, and other structures. In addition, Schmucker's students designed, constructed, and tested small bridges made of pasta and glue. Certain lessons about mechanics and analysis are clearly conveyed by working with these materials, so the project is an appropriate enhancement to the (typically junior-year) analysis course. There is not, however, a good link to the complex material idealizations so critical to the design courses that follow. Pessiki et al.[8] described an undergraduate laboratory with small-scale (bench-top) experiments including flexural strength of concrete beams, plastic bending of steel beams, and several non-destructive tests. The authors describe a significant component of course content focusing on the transducers and test setups. In this regard their lab seems to be directed largely toward preparing students for graduatelevel structural research work.

While small-scale models can be effective in illustrating elastic behaviors and some failure modes, large-scale specimens offer important advantages: First, construction techniques and constituent materials are the same as in the "real world," removing a layer of abstraction that is present with scaled specimens and allowing specimens to be designed to illustrate a full range of failure modes. Second, students in lower-division construction methods and materials courses participate in the fabrication of test specimens, so the activity is leveraged to provide a new focus for continuity in the academic program. Finally, the "wow factor" is significant and helps motivate students to understand related course material. This paper describes the kinds of experiments we have done, plans to increase our repertoire, and how we integrate this activity into the architectural engineering program.

The concept of the Structural Engineering Workshop is at the heart of the recent development of a structural testing lab at MSOE. At this undergraduate institution the limited resources available for laboratory development must be justified by the likely impact on undergraduate education, so the equipment and activities of the structural testing laboratory are designed around the needs of the undergraduate architectural engineering and construction 


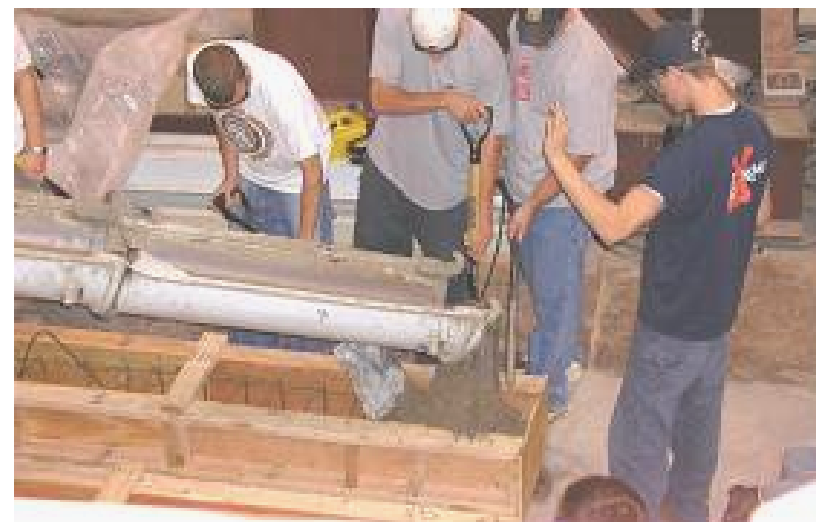

Figure 1. Students place concrete.

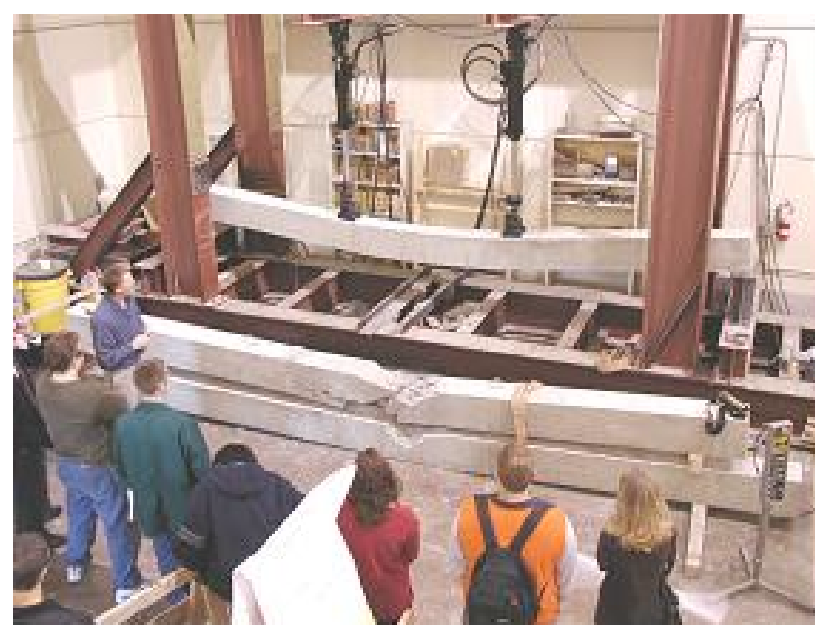

Figure 2. Students observe flexural tests.

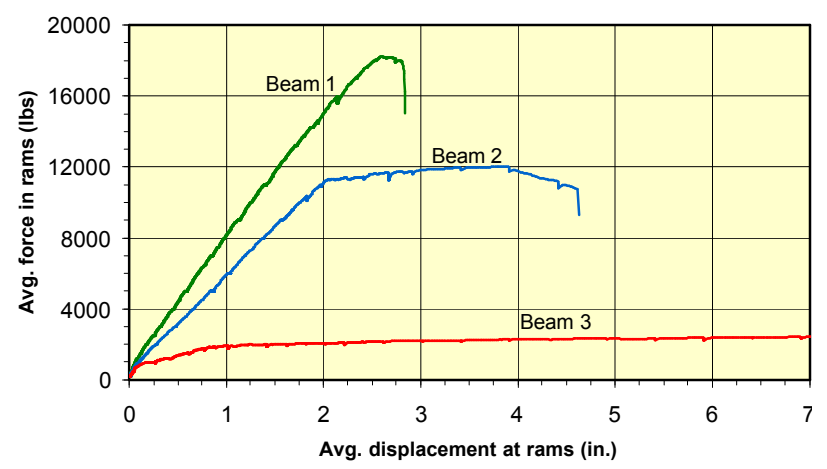

Figure 3. Flexural test results. management programs. Faculty and undergraduate research assistants do conduct sponsored research projects in the lab - and the lab's growing collection of tools, hydraulic test equipment, and instrumentation has benefited significantly from the budgets of these projects - but these projects must work around the schedule and space needs of the undergraduate classes that are scheduled to use the lab each term. The first major structural testing equipment acquisition for the lab was the result of an NSF Instrumentation and Laboratory Improvement grant awarded in 1998 (9851383). The proposal for the equipment grant described plans to incorporate testing of full-scale structural components into the advanced undergraduate structural engineering courses, and our initial experience with this activity led us to the concept of the SEW. Continued development of the SEW is funded by a grant (01-xxxxx) from the NSF Course, Curriculum, and Laboratory Improvement program.

\section{Laboratory Activities}

The core of the SEW is a series of largescale experiments for the advanced structural engineering classes. At this point we have conducted flexural tests of reinforced concrete beams, cyclical tests of wood framed shear walls, flexural tests of wood truss floor systems, plastic bending of steel sections, and non-destructive loading of a strain-gauged steel bar-joist. Different variations of each experiment are planned for each year, and additional experiments are planned. We are currently planning eccentric compression tests for reinforced concrete columns. A more complete description of the reinforced concrete beam flexural tests and the wood framed shear 
wall tests will serve to describe the content of the SEW.

Sophomore students in the construction methods course fabricate specimens for the reinforced concrete beam flexural tests and the wood framed shear wall tests. This is the students' first course on construction planning and it achieves its goals by focusing on five construction projects in the laboratory. The students learn to interpret engineering drawings and resolve the inconsistencies that inevitably come to light when all the details of a constructed object must be worked out. Teams of students plan a project one week and conduct it the next, but in the class's usual mode the project is a mock-up of some kind that is dismantled at the end of the lab period. Bringing the SEW into this course provides a real object for the students to build - and gives us "free labor" for fabricating test specimens. For example, three teams of students planned and fabricated the formwork for three twenty-foot long concrete beams, and three other teams placed and tied the steel reinforcing bars. Then individuals from these teams volunteered to meet the ready-mix truck and place and finish the concrete (see Fig. 1). None had previous experience doing this kind of work. One student who had spent a summer working for a construction inspection service was responsible for doing an initial slump test and approving the pour, then casting test cylinders while explaining the details of the process to others. In a different section of the construction methods course three teams planned and fabricated eight-foot square shear wall panels with various nailing patterns (see Fig. 4). While their tasks were less complex than those of the concrete beam teams, the students found important lessons in the details: ...the difference between a "sinker" and a "common" nail and why it matters to a structural engineer, nails at 3 inch spacing makes for sore forearms, adjusting nominal stud spacing on a drawing to actually fit on the object, etc.

The reinforced concrete beam flexural tests are conducted with the students in the advanced reinforced concrete design course (Fig. 2). The concepts illustrated are quite elementary, but we use the exercise as a review to ensure that the students understand the critical tradeoffs of ductility and strength - beams with three amounts of flexural reinforcement are used to achieve a range of results (Fig. 3). The students review the basic analysis of the beams before coming to the lab, so we have predictions of the loads to cause cracking moment, the loads to cause service moment and the corresponding deflection, and the ultimate loads. The lab experience starts with compression testing of cylinders to establish the basic concrete strength and the students adjust their calculations accordingly. Each beam test is conducted in load control up to about $90 \%$ of the predicted ultimate capacity, and then switched to displacement control so we can capture the ductile behavior as the reinforcement yields. The entire process including testing three beams takes about two hours.

The wood framed shear wall panel tests are conducted with students in the wood and masonry design course (Fig. 5). Students come to the lab with a prediction of wall capacity based on the nailing, panel type and thickness, and the hold-down hardware specifications. The cyclical displacement-controlled loading follows guidelines developed by the CUREE project to simulate seismic loading. This allows us to introduce the students to the idea of damage accumulation, and we can listen to and watch the damage rather than simply showing the resulting hysterysis loops (Fig. 6). 


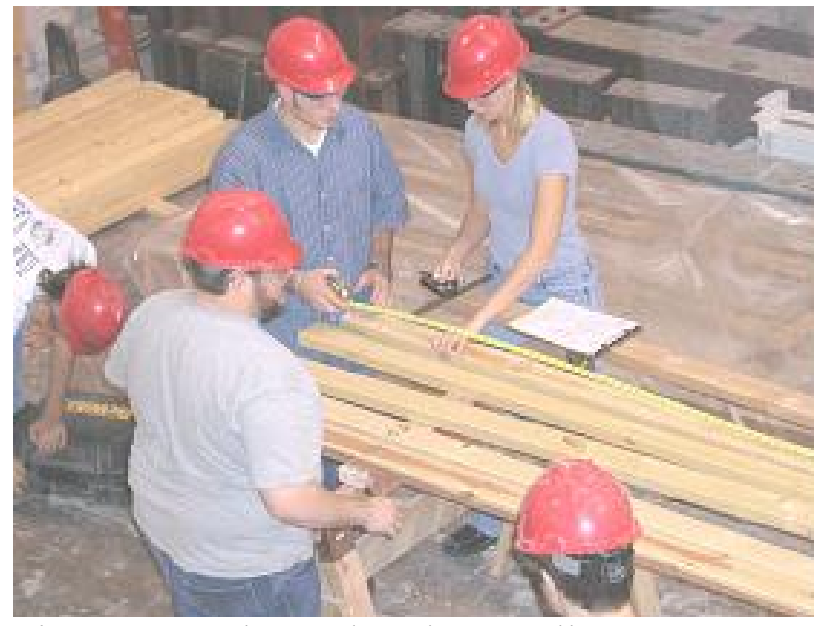

Figure 4. Students plan shear walls.

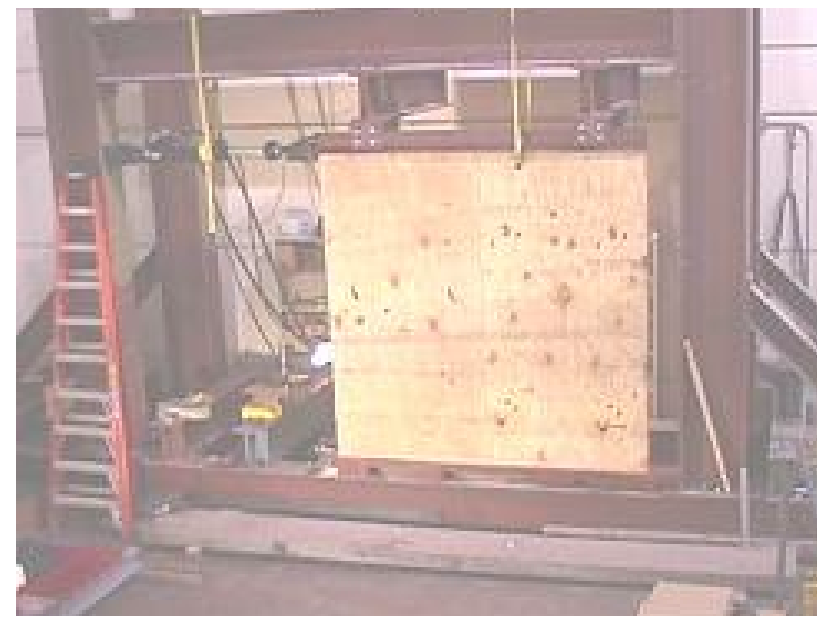

Figure 5. Cyclical shear wall test.

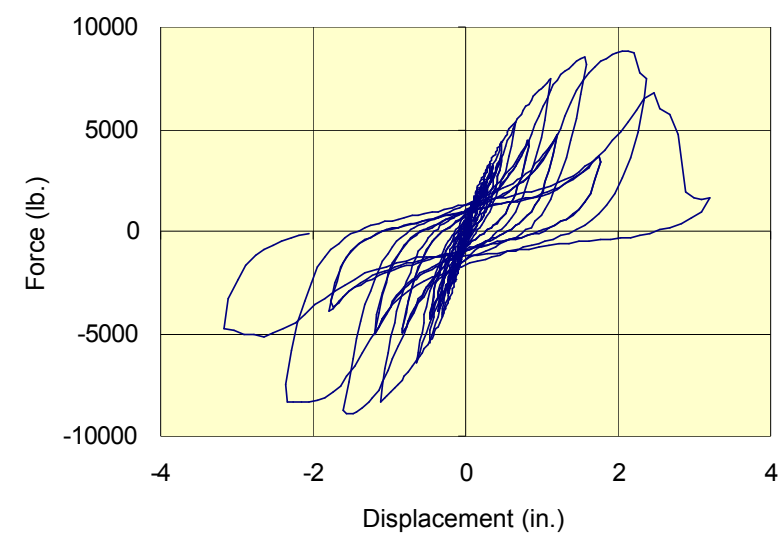

Figure 6. Shear wall test results.

\section{Related Activities}

When fully developed, the SEW will be an electronic book organized around individual structural components. Each module will include multimedia content designed to integrate the physical experiments into our curriculum, and basically to get the biggest bang for each buck devoted to the lab activities.

\section{A structural component in context}

The goal of this part of the module is to help the user understand the relationships between the component and the structure of which it is a part - to put the structural component into context. Information describes what the component physically is, how it is used, and what variations are common.

\section{Background theory}

This section will review aspects of material from engineering science courses that provide the fundamental knowledge for understanding the structural component's behavior. For example, understanding a reinforced concrete flexural test requires knowledge about basic statics, flexural stress and strain relationships, the Whitney stress block, etc.

\section{Interactive design calculations}

The goal is to fully explore the idealizations that are used in analysis and design of the component and the structure of which it is part. Multiple methods of analysis and design (LRFD, ASD, etc.) will be presented when appropriate. The effect of specific assumptions on the results of structural analysis will be illustrated by including multiple analyses.

\section{Multimedia record of full-scale experiment}


The goal of this section is to present real physical behavior of the component. As experiments are repeated over the years a database of results will allow students to explore the ideas of variability and reliability in structures.

\section{Summary-with links to the next step}

The goal of this section is to present a full discussion of the experimental results, evaluating observed behaviors of part 3 with regard to the design idealizations of part 2 and the applications of part 1 . Plots derived from the experimental data will be explained. The significance of differences between specimens will be discussed. Results will be used to evaluate the analysis (for example: "Do measured reactions or displacements match those from analysis? Why/why not?"), the experimental setup (for example: "If we had strain-gauged the rebar..."), and placement of the component in a system (for example: "If the beam were part of a continuous structure how would the behavior change?").

\section{Conclusions and further questions}

The experiments and related activities of SEW constitute a coherent curriculum in structural behavior that is overlaid on the traditional set of courses. Through exposure to different aspects of the experiments - planning, fabrication, testing, analysis - several times during their studies, students are encouraged to develop their own understanding of structural behavior.

The idea that the students' learning from these activities is not uniform has led to interesting discussions among faculty... Is it fair that all the students do not have an identical experience? In the construction methods course, for example, our intent is that each team of students should work on at least one type of test specimen (some work on formwork or rebar for concrete beams, some work on wood shear walls, some work on...) in addition to their other scheduled lab activities. So in answer to the "fairness" question, we try to provide comparable experiences when identical experiences are not practical. The goal of these activities, after all, is not for students to learn how to place concrete; rather it is for students to understand and become curious about the links between the structures they draw and those that are built.

Assessment of the SEW to this point has been informal. Summative evaluations planned will consist of short multiple-choice conceptual diagnostic tests given at two student education levels. The first evaluation will assess the project's effectiveness in conveying specific concepts ("shear cracks are expected to form at what angle?") and general ideas ("wood shear walls are an important part of what type of construction?") at the sophomore level. The second evaluation will include more detailed questions about structural design concepts. The goal of both evaluations is to determine whether or not the students think the SEW activities have helped them understand and increased their curiosity.

One last question we'll probably need some outside input to answer is this: Could the electronic book be useful to academic programs without means to conduct the physical experiments? The answer will depend on how well we implement our plans for this aspect of the project. 


\section{References}

1. Backman, L. 1993. “Computer-aided liability,” Civil Engineering 63(6). ASCE. pp. 40-43.

2. Behr, R. A. 1996. "Computer simulations versus real experiments in a portable structural mechanics laboratory," Computer Applications in Engineering Education 4(1). John Wiley and Sons, Inc., New York. pp. 9-18.

3. Belarbi, A., Behr, R. A., Karson, M. J., and Effland, G. E. 1994. "Formal assessment of the AN/EX structural engineering teaching laboratory," Computer Applications in Engineering Education 2(2). John Wiley and Sons, Inc., New York. pp. 109-121.

4. Brohn, D. M. 1996. "Engineering on the right," Structural Engineer 74(22). Institute of Structural Engineers, London. pp. 380-382.

5. Krawinkler, H., P. Francisco, L. Ibarra, A. Ayoub, and R. Medina. 2001. "Development of a testing protocol for woodframe structures," CUREE publication $W$-02. Consortium of Universities for Research in Earthquake Engineering, Richmond, CA.

6. Ferguson, E. S. 1993. "How Engineers Lose Touch," Invention and Technology winter 1993. pp. 16-21.

7. Parmelee, R. A. 1998. "Have we let computers replace structural engineering judgment?" Structure winter 1998. National Council of Structural Engineers Associations, Council of American Structural Engineers, and Structural Engineering Institute, Chicago. pp. 27-29.

8. Pessiki, S., Lu, L-W., and Yen, B. T. 1994. "Experiences with an undergraduate structural engineering laboratory," Proc. of Structures Congress XII. ASEE. pp. 1369-1374.

9. Petroski, H. 1985. To Engineer is Human: The Role of Failure in Successful Design. St. Martin's Press, New York.

10. Schmucker, D. G. 1998. "Models, models, models: the use of physical models to enhance the structural engineering experience," Proc. 1998 ASEE Annual Conf. ASEE. Session 3615.

11. Wadia-Fascetti, S . and Tarnowski, M. 1998. "Integrating problem solving and communication in the structural engin eering laboratory," Proc. 1998 ASEE Annual Conf. ASEE. Session 1275.

DOUG STAHL is an Associate Professor of Architectural Engineering and Building Construction and Director of the Construction Science and Engineering Center at MSOE. He received a doctorate in Civil Engineering from the University of Wisconsin - Madison in 1996, and holds Professional Engineer and Structural Engineer licenses.

FRITZ DEVRIES, Associate Professor of Architectural Engineering and Building Construction at MSOE, received his Ph.D. in Structural Engineering from the University of Texas at Austin in 1996. He has worked as a structural engineer in Texas, Oklahoma and Wisconsin, and is a licensed Professional Engineer.

Proceedings of the 2003 American Society for Engineering Education Annual Conference \& Exposition

Copyright 2003, American Society for Engineering Education 